\title{
Frequency of non-asthma GP visits predicts asthma exacerbations: an observational study in general practice
}

\author{
*Michael E Hyland ${ }^{1,6}$, Ben Whalley ${ }^{1,6}$, David MG Halpin ${ }^{2,6}$, Colin J Greaves ${ }^{3,6}$, Clare Seamark ${ }^{4,6}$, \\ Sue Blake ${ }^{4,6}$, Margaret Pinnuck ${ }^{4,6}$, David Ward ${ }^{4,6}$, Adam L Hawkins ${ }^{5,6}$, Dave Seamark ${ }^{4,6}$
}

\author{
${ }^{1}$ School of Psychology, University of Plymouth, Plymouth, Devon, UK \\ 2 Department of Respiratory Medicine, Royal Devon and Exeter Hospital, Devon, UK \\ ${ }^{3}$ Peninsula Medical School (Primary Care), Postgraduate Medical Centre, Barrack Road, Exeter, Devon, UK \\ ${ }^{4}$ Honiton Group Practice, Marlpits Lane, Honiton, Devon, UK \\ ${ }^{5}$ GSK(UK), Uxbridge, Middlesex, UK \\ ${ }^{6}$ East Devon Respiratory Research Group, Marlpits Lane, Honiton, Devon, UK
}

Originally received 26th March 2012; resubmitted 3rd May 2012; revised version received 15th May 2012; final revision 17th May 2012; accepted 17th May 2012; online 26th July 2012

\begin{abstract}
Background: Being able to identify patients at risk of exacerbations is useful as it enables resources to be targeted at these patients.

Aims: To test the theoretically-derived prediction that the frequency of non-asthma related visits to the general practitioner (GP) predicts exacerbations.

Methods: Clinical and demographic data and both self-report and prescription-based adherence data were obtained from 166 patients diagnosed with asthma attending a GP clinic, all of whom were prescribed inhaled corticosteroids (ICS). Asthma exacerbations (treated by the GP or in hospital) and non-asthma visits and symptoms were assessed from notes for the subsequent 5 years.

Results: Exacerbations correlated with non-asthma visits (0.35), severity as measured by BTS step (0.28), and with prescription-based adherence (0.28). Asthma severity correlated with non-asthma visits (0.35). Receiver operating curves showed that $\geq 2$ non-asthma visits per year provided $79 \%$ sensitivity and $58 \%$ specificity for detecting $\geq 3$ exacerbations over 5 years. Poor adherence predicted outcomes only for patients with high levels of non-asthma visits $(\geq 3)$ and only for those reporting regular-but-less ICS use but not symptom-directed ICS use.

Conclusions: Non-asthma visits are a good predictor of asthma exacerbations, particular in non-adherent patients. These results are consistent with a mechanism where exacerbations result from a combination of random oscillating specific and non-specific inflammatory processes. It is important to consider the total patient rather than just the lung when managing patients with asthma.

(C) 2012 Primary Care Respiratory Society UK. All rights reserved.

ME Hyland et al. Prim Care Respir J 2012; 21(4): 405-411

http://dx.doi.org/10.4104/pcrj.2012.00061
\end{abstract}

Keywords exacerbation, asthma, adherence, management, GP visits, consultations, frequency

See linked editorial by Griffiths \& Clark on pg 368

The full version of this paper, with online appendices,

is available online at www.thepcrj.org

\section{Introduction}

Many patients who have serious asthma exacerbations have severe asthma or are non-adherent with inhaled corticosteroids (ICS). ${ }^{1-3}$
However, population studies show that the correlations between adherence, severity and exacerbations are poor. ${ }^{4}$ Only a minority of non-adherent patients go on to experience exacerbations, ${ }^{5}$ and exacerbations are not restricted to patients with severe asthma.

There are two interpretations of these data. One is that, apart from lifestyle events, adherence and severity are the only causal factors. Irrespective of severity, non-adherent patients with or without problems differ only because the latter have been lucky - so far. All non-adherent

\footnotetext{
* Corresponding author: Professor Michael E Hyland, School of Psychology, University of Plymouth, Plymouth PL4 8AA, UK.

E-mail: mhyland@plymouth.ac.uk
} 
patients are at risk, and resources for asthma education should therefore be evenly distributed across all patients. The second interpretation is that some other mechanism determines whether or not non-adherent patients have problems. If this second interpretation is true, resources for asthma education should be targeted at those for whom non-adherence is likely to be a problem and a screening tool for identifying patients at risk of exacerbations would be helpful.

We tested the theory-based prediction ${ }^{6}$ that dysregulated asthma patients have a higher risk of exacerbations. The concept of the dysregulated patient (i.e. one who has multiple non-specific health problems) follows from network theory ${ }^{7}$ and the assumption that the body functions in part as a network system. ${ }^{6,8,9}$ If the body exhibits network (i.e. parallel distributed processing) functionality, then stress and other adverse circumstances could lead to systemic immune and neurological disturbance, frequent somatic and psychological symptoms, and poor coping. ${ }^{6}$ We reasoned that high attendance for non-asthma-related problems to see a general practitioner (GP) is an indicator of dysregulation. We predicted that non-adherent asthma patients who require frequent GP response for non-asthma-related events would have more asthma exacerbations than non-adherent patients who attend infrequently. However, if all non-adherent patients are at risk, then there would be no relationship between non-asthma attendance and asthma exacerbations.

\section{Methods}

\section{Patient sample and baseline assessment}

This study obtained data through an examination of patient records at a semi-rural general practice clinic in south-west England where asthma education is provided by a trained respiratory nurse. We used baseline data from 185 patients who (in 2001-2002) had responded to questions on asthma medication usage (64\% of the 202 patients contacted) as part of a separate study on adherence. ${ }^{5}$ The inclusion criterion for these patients was that they were prescribed ICS; there were no exclusions. Of the 185 patients, 176 could be classified according to their responses as 'regular' (i.e. taking the medication twice a day as instructed), 'regular-but-less' (i.e. taking the same amount every day but less than recommended), or 'symptom-directed' (i.e. varying the dose according to symptoms) users of preventive medicine (in all cases including but not limited to ICS). Additionally, inspection of prescription records over the previous 3 years was used to classify patients' ICS use as either adequate $(75 \%$ or more of recommended prescriptions) or inadequate (less than $75 \%$ of recommended prescriptions). The patient's age and British Thoracic Society (BTS) step of treatment were also recorded.

In the present study we carried out a manual search of notes for the 5 years after baseline. Of the original 176 patients, three died during the subsequent 5 years and the notes were unavailable for seven patients; our analysis is based on 166 patients for whom we had self-report adherence data and whose notes were available for up to 5 years follow-up. Ethical approval was obtained from the local research ethics committee.

\section{Measures}

A classification manual was developed by members of the research team and was used to classify medical contact for the 166 available patients under two headings: asthma exacerbations and nonasthma visits.

Asthma exacerbations were defined as an increase in symptoms resulting in a non-routine visit to the GP office or hospital accident and emergency department (with or without admission) and leading to nebulisation, a course of corticosteroid tablets, or increased preventer medication. Events more than 3 weeks apart were counted separately.

Non-asthma visits were defined as all contacts with GPs (in office hours, out of hours, face-to-face, or by telephone) and visits to the emergency department that were not asthma-related. Contact with nurses and other healthcare professionals and consultant letters were not counted. Presenting symptoms for each non-asthma visit were classified and counted up within each of 10 categories.

\section{Statistics}

Pro rata adjustments of visit and exacerbation frequency were made if patient records were unavailable for the full 5 years. Correlations were calculated using Spearman correlations. Receiver operating characteristic (ROC) analysis was used to estimate sensitivity and specificity for frequency of non-asthma visits in predicting 2, 3, 4, or $\geq 5$ asthma exacerbations during the study period.

Follow-up analyses used zero-inflated Poisson regressions to estimate annual rates of exacerbations and the interaction between non-asthma visits and adherence. The exposure offset was months of available data; BTS step was used to predict zero inflation. We examined the effect of adherence and the number of non-asthma GP visits on exacerbations. Including interaction terms allowed us to estimate non-additive effects of non-asthma visits and adherence on the model. Sensitivity analyses included additional models conditioned on age and patient gender (these models are not reported here but the pattern of inference remained unchanged). Model means and contrasts were computed by the delta method; all analyses were completed in Stata $12 .{ }^{10}$

A completed STROBE checklist is shown in Appendix 1 (available online at www.thepcrj.org)

\section{Results}

\section{Descriptive data}

UK Office for National Statistics data ${ }^{11}$ indicate that the practice catchment is urban, slightly older than the national average (46.4 vs. 38.6 years), ethnically homogeneous (97.5\% White/British vs. $86.9 \%$ across the UK), and with a higher than average burden of long-term limiting illness $(24.6 \%$ vs. $20.3 \%$ for the surrounding area and $17.9 \%$ for the UK); only $12.2 \%$ had attained a university or equivalent qualification compared with a UK average of $19.9 \%$. In our sample, patients' mean age was 42 years (SD 10.6, range 21-61). Fifty patients (35\%) were male, and men and women were of equivalent age ( $p>0.3)$. At baseline, $134(81 \%)$ were at British Thoracic Society (BTS) treatment step 2, 26 (14\%) at step 3, and eight $(5 \%)$ at step 4 . Records were available for the full 5 years for 153 (92\%) patients; only one patient had data available for <2 years.

Fifty-four patients reported regular use of ICS, 23 reported regular use but at suboptimal dose (regular-but-less), and 89 
Table 1. Three-way frequencies for BTS step, self-

reported adherence styles, and prescription-based inhaled corticosteroid (ICS) usage from baseline data

\begin{tabular}{lllll} 
& BTS step 2 (N=134) & BTS step $>2(\mathrm{~N}=32)$ \\
\hline \multicolumn{5}{c}{ ICS use (prescription records) } \\
\hline $\begin{array}{l}\text { Reported } \\
\text { adherence }\end{array}$ & Inadequate & Adequate & Inadequate & Adequate \\
\hline Regular & 19 & 18 & 7 & 10 \\
\hline $\begin{array}{l}\text { Regular-but- } \\
\text { less }\end{array}$ & 12 & 5 & 2 & 4 \\
\hline $\begin{array}{l}\text { Symptom- } \\
\text { directed }\end{array}$ & 73 & 7 & 6 & 3
\end{tabular}

reported symptom-directed use. Inspection of prescription records showed that 47 patients (28\%) had adequate ICS use and 119 $(72 \%)$ had inadequate use. The relation between the two types of adherence assessment for each BTS step is shown in Table 1. Estimates of adherence depend on the method of assessment used. Figure 1 shows the frequency of non-asthma visits over the 5-year period.

The Spearman correlation between asthma exacerbations and non-asthma visits was $0.35(p<0.001)$, with BTS step was 0.28 $(p<0.001)$, with self-reported adherence was $0.13(p=0.10)$, and with adherence by prescription records was $0.21(p=0.007)$. Nonasthma visits were not significantly correlated with BTS step or with either measure of adherence. BTS step correlated with both selfreported adherence $(0.19, \mathrm{p}=0.013)$ and with prescription records (0.29, $\mathrm{p}=0.002$ ).

Table 2 shows exacerbations as a function of self-reported adherence and BTS step. Overall, more exacerbations were attributable to patients at step 2 (120 exacerbations) than at step 3 (58 exacerbations), and the majority of patients ( $n=107,64 \%$ ) had no exacerbations during the 5 -year period.

\section{Non-asthma visits as predictors of asthma exacerbations}

First, we explored how useful non-asthma GP attendance was at predicting different numbers of exacerbations over the 5-year study period. ROC curves were computed using non-asthma visits to identify patients who experienced $\geq 2,3,4$ or 5 exacerbations during the study period. Areas under the curve (AUCs) ranged from 0.72 (for two exacerbations) to 0.82 (for five or more). A screening tool
Figure 1. Frequency of non-asthma visits over the 5-year study period

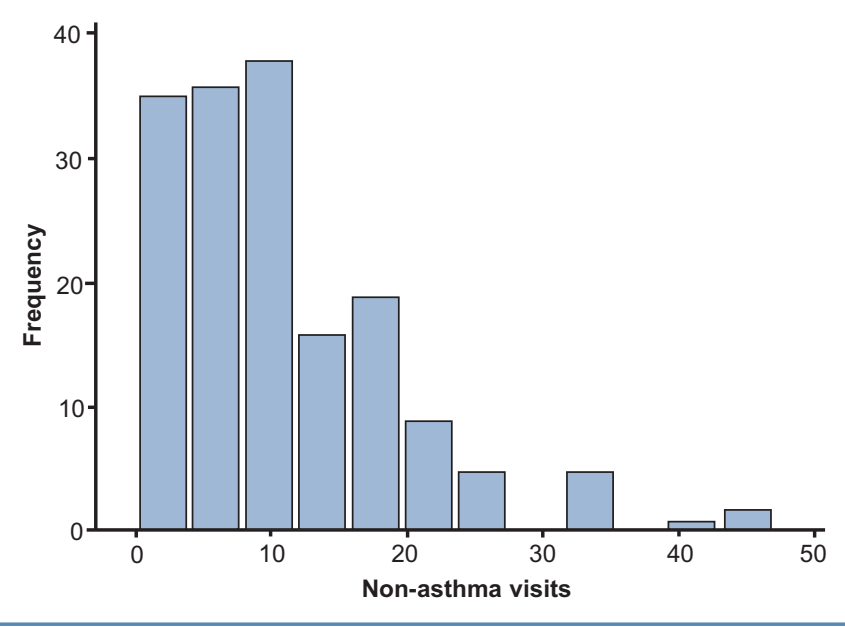

that identifies the $10 \%$ of patients most at risk of exacerbations would be useful for GPs in prioritising resources. Nineteen patients $(11 \%)$ in our sample experienced $\geq 3$ exacerbations during the study period, so this level of morbidity was selected as a criterion for poor control. The ROC curve for non-asthma visits predicting $\geq 3$ exacerbations over 5 years is presented in Figure 2; total AUC was 0.75 (95\% Cl 0.63 to 0.87$)$. Sensitivity and specificity at different thresholds are presented in Table 3. For comparison, we also computed ROC curves for BTS step, self-reported adherence, and ICS usage, each predicting the same outcome of $\geq 3$ or more exacerbations in the study period. For BTS step the total AUC was $0.66(95 \% \mathrm{Cl} 0.54$ to 0.78$)$, but sensitivity for BTS step at a threshold of $\geq 3$ was only $47 \%$ and for a threshold of step $\geq 4$ the sensitivity was $15 \%$. For symptom-directed vs. regular adherence the AUC was only 0.37 (95\% Cl 0.24 to 0.51$)$ and, for regular-butless vs. regular adherence, the AUC was only 0.51 ( $95 \% \mathrm{Cl} 0.36$ to 0.65). For ICS usage the AUC was only 0.30 ( $95 \% \mathrm{Cl} 0.19$ to 0.42 ).

There was a statistically significant but very small effect of age such that each additional year predicted an increase of 0.007 exacerbations $(p=0.001)$. We found that women were significantly more likely to experience an exacerbation than men $(0.13$ more exacerbations per year, $\mathrm{p}=0.006$ ) but the interaction between gender and non-asthma visits was not-significant $(p=0.96)$,

Table 2. Total number of exacerbations and number and proportion of patients having 0,1 or 2 , and $\geq 3$ exacerbations over the 5-year study period

\begin{tabular}{|c|c|c|c|c|c|c|}
\hline & BTS step 2 & & & BTS step & & \\
\hline & Regular & $\begin{array}{l}\text { Regular- } \\
\text { but-less }\end{array}$ & $\begin{array}{l}\text { Symptom- } \\
\text { directed }\end{array}$ & Regular & $\begin{array}{l}\text { Regular- } \\
\text { but-less }\end{array}$ & $\begin{array}{l}\text { Symptom- } \\
\text { directed }\end{array}$ \\
\hline Number of patients & 37 & 17 & 80 & 17 & 6 & 9 \\
\hline Total number of exacerbations & 36 & 23 & 61 & 28 & 16 & 14 \\
\hline Patients with no exacerbations, $\mathrm{n}(\%)$ & $23(62)$ & $13(76)$ & $58(73)$ & $7(41)$ & $3(50)$ & $3(33)$ \\
\hline Patients with 1 or 2 exacerbations, $\mathrm{n}(\%)$ & $9(24)$ & $3(18)$ & $18(23)$ & $6(35)$ & $0(0)$ & $4(44)$ \\
\hline
\end{tabular}


Figure 2. Receiver operating characteristic (ROC) curve for non-asthma visits predicting $\geq 3$ exacerbations over 5 years

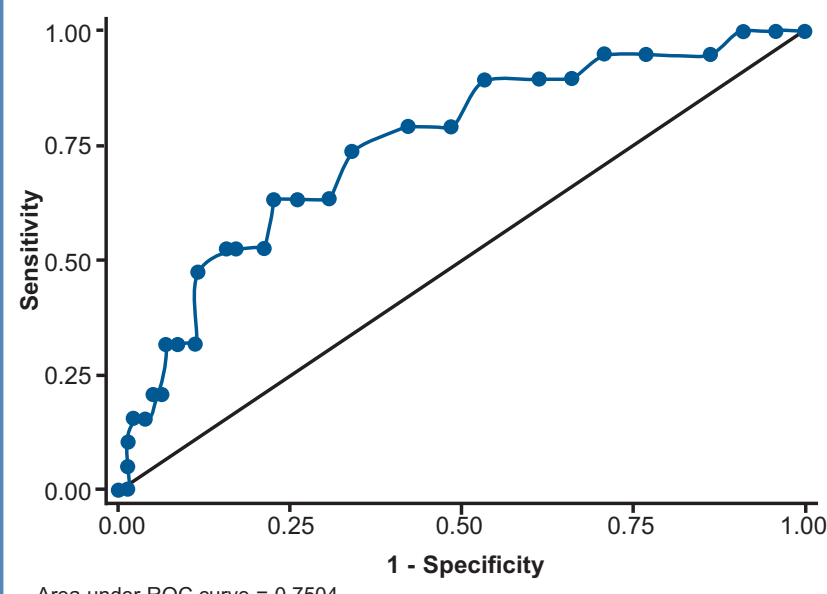

Area under ROC curve $=0.7504$

Table 3. Sensitivity and specificity at various numbers of non-asthma visits per year predicting $\geq 3$ asthma

exacerbations during 5-year study period

\begin{tabular}{llll} 
& \multicolumn{4}{l}{ Threshold (non-asthma visits per year) } \\
\hline & $\geq 2$ & $\geq 3$ & $\geq 4$ \\
\hline Prevalence, N (\%) & $69(41.6)$ & $45(27.1)$ & $25(15.1)$ \\
\hline Sensitivity, \% & 78.9 & 63.2 & 31.6 \\
\hline Specificity, \% & 57.8 & 77.6 & 77.5
\end{tabular}

indicating that the relationship between non-asthma visits and asthma exacerbations was consistent between men and women.

In addition to the number of non-asthma visits, we collected data on the symptoms with which patients presented on each occasion. As a further exploratory analysis, we examined whether particular symptoms were associated with higher levels of exacerbations. Identical ROC analyses (uncorrected for multiple comparisons) were performed for the numbers of visits related to each of the 10 symptom types. Areas under the curve are presented in Table 4. Patients presenting with ENT symptoms were most likely to experience $\geq 3$ exacerbations, but moderate AUCs were also observed for gastrointestinal symptoms, musculoskeletal symptoms, and symptoms given a psychological attribution. Cardiovascular, eyerelated and genitourinary symptoms did not identify patients with high exacerbation rates. As a supplementary analysis, we examined the notes of the 15 patients who had the most frequent exacerbations. All were female and nine were receiving medication for depression (see Appendix 2 available online at www.thepcrj.org).

\section{Adherence and non-asthma visits as predictors of exacerbations}

Regression results revealed that both non-asthma visits (incidence rate ratio $1.04,95 \% \mathrm{Cl} 1.02$ to 1.05 ) and indicators for adherence style (likelihood change: $\chi^{2}[1]=13.07, \quad p=0.001$ ) predicted
Table 4. Area under the ROC curve (AUC) for nonasthma visits categorised by symptoms and predicting $\geq 3$ asthma exacerbations (Cls uncorrected for multiple comparison)

\begin{tabular}{lll} 
Symptom & AUC & $95 \% \mathrm{Cl}$ \\
\hline ENT & 0.76 & 0.65 to 0.87 \\
\hline Gastrointestinal & 0.69 & 0.55 to 0.83 \\
\hline Musculoskeletal & 0.66 & 0.55 to 0.78 \\
\hline Psychological & 0.66 & 0.53 to 0.79 \\
\hline Neurological & 0.61 & 0.50 to 0.73 \\
\hline Dermatological & 0.61 & 0.49 to 0.73 \\
\hline Psychiatric & 0.60 & 0.48 to 0.72 \\
\hline Women's health & 0.59 & 0.46 to 0.71 \\
\hline Genitourinary & 0.56 & 0.43 to 0.69 \\
\hline Eyes & 0.55 & 0.44 to 0.66 \\
\hline Cardiovascular & 0.49 & 0.39 to 0.58
\end{tabular}

exacerbations. Follow-up contrasts indicated that, compared with regular use, only patients reporting the regular-but-less pattern experienced greater exacerbations per year (difference $0.23,95 \% \mathrm{Cl}$ 0.09 to 0.36 ). Symptom-directed medication use was not significantly associated with an increase in exacerbations compared with regular use (difference $0.04,95 \% \mathrm{Cl}-0.02$ to 0.10 ). Vuong tests $^{12}$ indicated that zero-inflated models using BTS step and age performed better than unadjusted Poisson models (all $p$ values $<0.001)$

Additional models examined the combined predictive value of non-asthma visits and adherence style. Figures 3 and 4 show the relationship between asthma exacerbations and non-asthma visits (model-predicted exacerbations per year) split between the three reported adherence styles or the two categories of ICS usage identified on the basis of prescription records.

Table 5 presents contrasts between patients who reported regular adherence and those who reported regular-but-less or symptom-directed adherence; these contrasts were computed for patients with median, moderate, high or very high numbers of nonasthma visits (defined as 2, 3, 4 or 5 non-asthma visits per year, and approximately equivalent to the 50th, 75th, 90th and 95th centiles in the sample). Exacerbations did not differ between patients reporting regular or symptom-directed adherence patterns. However, when examining patients with moderate or greater numbers of non-asthma visits, those reporting regular-but-less adherence experienced significantly more exacerbations than those with regular or symptom-directed adherence, equating to 0.35 additional exacerbations per year for regular-but-less patients who had high numbers of non-asthma visits.

An interaction was also found between ICS usage (based on prescription records) and non-asthma visits. Inadequate ICS use predicted significantly fewer exacerbations per year for patients who made two non-asthma GP visits (difference -0.093 exacerbations, $95 \% \mathrm{Cl}-0.215$ to -0.013$)$. However, patients who combined inadequate ICS usage with moderate or higher non-asthma visits 
Figure 3. Relationship between asthma exacerbations and non-asthma visits for the three reported adherence styles

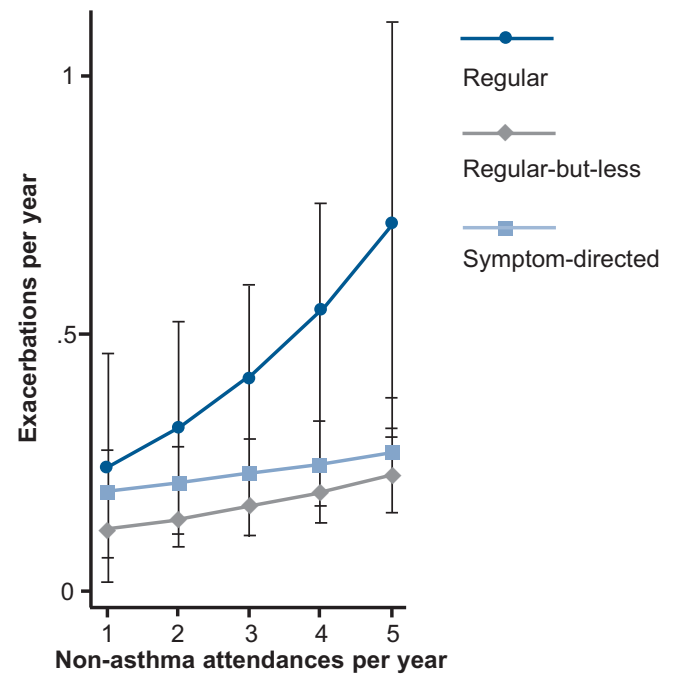

Figure 4. Relationship between asthma exacerbations and non-asthma visits for the two categories of inhaled corticosteroid (ICS) usage identified on the basis of prescription records

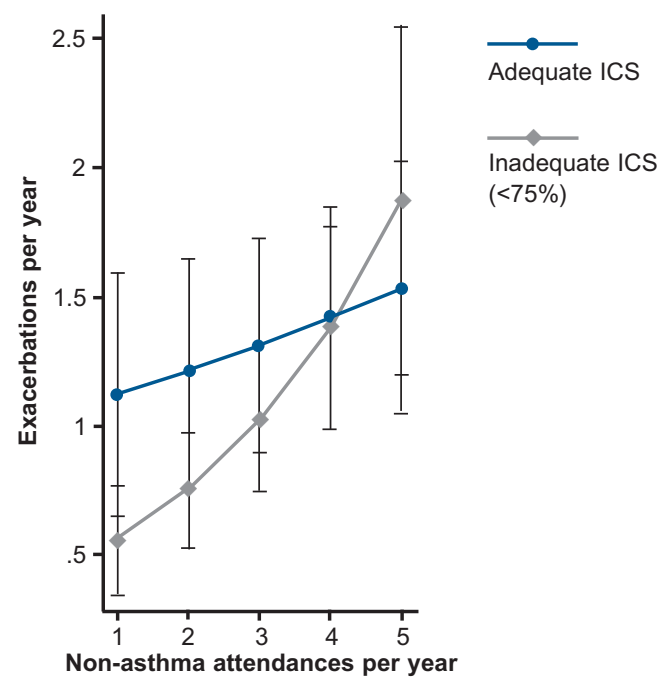

experienced significantly more exacerbations (likelihood ratio test comparing additive with multiplicative models: $\chi^{2}(1)=7.48, p=0.006$ ).

\section{Discussion}

\section{Main findings}

Severity (as measured by BTS step) predicted exacerbations $(r h o=0.28)$, as did non-asthma visits $(r h o=0.35)$. There was a nonsignificant trend for those reporting non-adherence to have fewer exacerbations and those deemed non-adherent by prescription records had significantly fewer exacerbations $($ rho $=0.21)$. One reason
Table 5. Differences in asthma exacerbations between adherent (regular) and non-adherent (regular-but-less or symptom-directed) patients at different levels of nonasthma attendances

\begin{tabular}{|c|c|c|c|c|}
\hline \multirow{2}{*}{$\begin{array}{l}\text { Non- } \\
\text { asthma } \\
\text { visits } \\
\text { (per year) }\end{array}$} & \multicolumn{2}{|c|}{$\begin{array}{l}\text { Regular-but-less } \\
\text { adherence }\end{array}$} & \multicolumn{2}{|c|}{$\begin{array}{l}\text { Symptom-directed } \\
\text { adherence }\end{array}$} \\
\hline & $\begin{array}{l}\text { Additional } \\
\text { exacer- } \\
\text { bations }\end{array}$ & $95 \% \mathrm{Cl}$ & $\begin{array}{l}\text { Additional } \\
\text { exacer- } \\
\text { bations }\end{array}$ & $95 \% \mathrm{Cl}$ \\
\hline $\begin{array}{l}2 \\
\text { (median) }\end{array}$ & 0.177 & -0.090 to 0.444 & 0.069 & -0.039 to 0.178 \\
\hline $\begin{array}{l}3 \\
\text { (moderate) }\end{array}$ & 0.251 & 0.020 to 0.481 & 0.063 & -0.037 to 0.163 \\
\hline $\begin{array}{l}4 \\
\text { (high) }\end{array}$ & 0.350 & 0.092 to 0.609 & 0.054 & -0.056 to 0.164 \\
\hline $\begin{array}{l}5 \\
\text { (very high) }\end{array}$ & 0.485 & 0.002 to 0.968 & 0.042 & -0.101 to 0.185 \\
\hline
\end{tabular}

why severity and adherence are not better predictors is that these two variables are confounded - more severe patients tend to be more adherent. By contrast, non-asthma visits were uncorrelated with either severity or adherence. Although severity predicts exacerbations, in this population twice as many exacerbations were recorded for patients at BTS step 2 than at higher steps.

We examined to what extent the frequency of non-asthma visits is a useful tool for identifying patients most at risk in the general practice population. Two non-asthma visits per year gave approximately $79 \%$ specificity and $58 \%$ sensitivity for detecting the $10 \%$ of patients in this population with the most exacerbations (i.e. $\geq 3$ asthma exacerbations over a period of 5 years). Three nonasthma visits per year gave $63 \%$ specificity and $77 \%$ sensitivity for detecting the same group. Thus, two non-asthma visits per year is a useful indicator that the patient is more likely to be at risk of an exacerbation. If patients have three non-asthma visits per year, they are more likely to be at risk, but this criterion will tend to miss a greater proportion of patients. The criterion of two non-asthma visits per year may therefore be a useful guide to alert clinicians that extra care is needed. The prediction of exacerbations from nonasthma visits is independent of gender, although females tended to have slightly more exacerbations.

The combination of non-asthma visits and adherence provides additional information about exacerbation risk. We used two prospective measures of adherence - prescription records and selfreport - and these two measures produce non-equivalent estimates of adherence. Self-report measures depend on memory, and prescription records do not tell whether the medication has been taken and if so by whom. At low frequencies of non-asthmarelated visits, low adherence as measured by prescription records was associated with fewer exacerbations, but at $\geq 5$ non-asthma visits per year it was associated with more exacerbations. These results provide insight into the variability of adherence-outcome results in population studies. ${ }^{4}$

Our measure of self-reported adherence identified three distinct patterns of medication use: regular, regular-but-less, and symptom-directed. We found that self-reported non-adherence 
(regular-but-less or symptom-directed) made no difference at low levels of non-asthma visits. At high or very high levels of nonasthma visits, self-reported non-adherence was prospectively associated with increased numbers of asthma exacerbations, but only for those in the regular-but-less category.

Surprisingly, we found no difference between symptomdirected and regular users of ICS at any level of non-asthma visits. Many guidelines recommend regular twice-daily use of ICS. Clinical trials where patients are assigned to symptom-directed versus regular use have produced variable results, but it has been suggested that symptom-directed ICS use in mild asthma may be safe for mild asthma. ${ }^{13-15}$ Additionally, many respiratory nurses recommend symptom-directed use for a proportion of their patients, ${ }^{16}$ but this recommendation is controversial. Our research, where patients choose rather than are allocated to the type of regimen, adds a different perspective to clinical trial data. The respiratory nurse in this practice, like others, recommends symptom-directed use of ICS in some patients. Some symptomdirected patients in this sample are therefore non-adherent to guidelines but adherent with what they have been told. We found that patients who choose the symptom-directed strategy had the same risk of exacerbations as regular users, which may reflect the selection of patients for different types of management strategy. Nevertheless, for neither regular nor symptom-directed use is the risk of exacerbations zero. It remains unclear whether the exacerbations that occurred in the minority of symptom-directed patients (of whom some had $\geq 3$ exacerbations) would have been reduced with regular use of ICS.

\section{Strengths and limitations of the study}

One strength of our study is that it is a 5-year analysis of objective practice data in a population of asthma patients coupled with a questionnaire. The limitations are that it was conducted in a single semi-rural practice that is not representative of the national population and the sample size is small, particularly for examining the relationship between type of visit and exacerbations. Adherence (measured at the start of our study) may change over time. Additionally, the reliability of adherence assessment, either by selfreport or by prescription records (both of which may underestimate adherence), may reduce the ability to detect the associations examined. Nevertheless, assessment of non-asthma visits is readily accessible in general practice and so could provide a pragmatic tool for identifying asthma patients with a high risk of future exacerbations.

\section{Interpretation of findings in relation to previously published research}

Asthma is a disease with airways-specific and non-specific (systemic) inflammatory components, and where the non-specific component may exacerbate the specific inflammation in the lung. Non-specific inflammation (e.g. raised levels of tumour necrosis factor $\alpha$, interleukin 1, interleukin 6) is increased by stress, ${ }^{17}$ is associated with an adverse psychological state, ${ }^{18,19}$ contributes to other specific inflammatory diseases ${ }^{20}$ may be a cause of medically unexplained symptoms, ${ }^{21}$ and is raised in asthma patients experiencing stress. ${ }^{22}$ Our study was motivated by the hypothesis that non-specific inflammation is associated with a phenotype of 'the dysregulated patient ${ }^{\prime 6}$ who presents with higher than average levels of somatic and psychological symptoms. We found preliminary evidence that symptoms associated with inflammatory mechanisms are particularly strong predictors of exacerbations (ENT, gastrointestinal, musculoskeletal, and psychological symptoms). The relation between poor asthma outcome and psychological morbidity has been established elsewhere, $1,2,23,24$ as has the relationship between exacerbations and severe nasal sinus disease or gastro-oesophageal reflux. ${ }^{23}$ All these data are consistent with a common non-specific inflammatory syndrome that increases asthma severity and nonasthma-related symptoms. Non-specific inflammation is associated with dysphoric psychological states ${ }^{21}$ which are known to be associated with maladaptive coping strategies.

\section{Implications for future research policy and practice}

Our study does not elucidate the exact mechanism for the relationship between non-asthma visits and exacerbations. It may be that dysregulated patients have a particularly maladaptive non-adherent selfmanagement style (i.e. a behaviourally mediated effect), or it may be that specific and non-specific inflammatory components interact (i.e. a biologically-mediated effect), or some combination of the two. Further research is needed to investigate the mechanisms underlying our findings. Replication in a larger sample would provide better information about the kind of non-asthma visits that are linked to asthma exacerbations, and therefore provide a better description of the non-asthma characteristics of the high exacerbator. An examination of the longitudinal relationship between non-asthma visits and asthma exacerbations would provide a better indicator of non-specific inflammatory involvement, as would assessment of non-specific inflammatory markers. Such data could help determine whether our observed relationship is biologically or behaviourally mediated.

Nevertheless, our research provides preliminary evidence that it is possible to identify the $10 \%$ of asthma patients most at risk from asthma exacerbations from the frequency of their non-asthmarelated health problems. We believe that we have identified a simple tool that will help GPs identify and target resources for at-risk patients. Two non-asthma-related visits per year should be treated as an indicator of risk of exacerbations, and clinicians should pay particular attention to adherence in these patients.

However, even where records of non-asthma visits are unavailable, our research suggests that effective asthma management requires the clinician to be aware of the non-asthmarelated health problems of the patient, particularly those relating to psychological disturbance, musculoskeletal and gastric problems and sinusitis. Patients who have these additional symptoms (some of which may be medically unexplained), particularly if they are female, are at greater risk of exacerbations than those who do not report these additional symptoms. As yet we have no clear way of helping these dysregulated patients beyond the need for better vigilance and enhanced education. The underlying theory which guided this research ${ }^{6}$ proposes that dysregulation and dysfunctionality arise from lifestyle patterns, in particular lifestyle stressors. It is not easy to modify the lifestyle of patients who experience real and difficult challenges in their daily lives. 


\section{Conclusions}

Our results suggest that a focus on medication adherence and severity alone misses an important factor that affects asthma outcome. The 'dysregulated' or 'dysfunctional' patient with multiple non-specific health problems is - particularly when non-adherent the patient most at risk and therefore most likely to benefit from educational interventions.

\section{Handling editor Mike Thomas \\ Statistical review Gopal Netuveli}

Conflicts of interest The authors believe that there is no conflict of interest as the results do not have commercial implications for drug or device manufacturers. However, the following authors have received sponsorship of one form or another in the last five years. MEH has attended a workshop organised by the IPCRG and funded by Novartis. CJG has provided paid consultancy for Eli Lilly and a paid workshop for Novartis. DMGH has received sponsorship to attend international meetings and honoraria for lecturing, attending advisory boards and preparing educational materials from Nycomed, AstraZeneca, Boehringer Ingelheim, Chiesi, GlaxoSmithKline, Novartis, MSD and Pfizer. His department has received research funding from AstraZeneca. ALH is Senior Area Medical Adviser for GlaxoSmithKline (UK). This study received a grant of $\mathrm{f} 5000$ from GlaxoSmithKline which paid for the coding of patient notes.

Contributorship MEH proposed the research question, took part in discussion at the design stage of the study, contributed to the interpretation of results and wrote the first draft of the paper with the exception of the statistics and results section. BW carried out the statistical analysis, wrote the first draft of the statistics and results section and contributed to the interpretation of results and to the final draft of the paper. DS and CS designed the classification manual and contributed to discussion at the design stage of the study, to the interpretation of the results and to the final draft. SB carried out the coding and contributed to discussion at the design stage of the study and to the final draft. DMGH, CJG, DW, MP and ALH contributed to discussion at the design stage of the study, to the interpretation of the results and to the final draft.

Funding Financial support towards the study was provided in the form of a medical grant by GSK(UK).

\section{References}

1. Sturdy PM, Victor CR, Anderson HR, et al. Psychological, social and health behaviour risk factors for deaths certified as asthma: a national case-control study. Thorax 2002;57:1034-9. http://dx.doi.org/10.1136/thorax.57.12.1034

2. Harrison B, Stephenson P, Mohan G, Nasser S. An ongoing confidential enquiry into asthma deaths in the Eastern region of the UK 2001-2003. Prim Care Respir J 2005;14:303-13. http://dx.doi.org/10.1016/j.pcrj.2005.08.004

3. Gamble J, Stevenson M, McClean E, Heaney LG. The prevalence of nonadherence in difficult asthma. Am J Respir Crit Care Med 2009;180:817-22. http://dx.doi.org/10.1164/rccm.200902-01660C

4. Osman LM, Hyland ME. Adherence and self management. In: Gibson P, Abramson M, Costabel U, Hensley M, Volmink J, Wood-Baker R, eds. Evidence based respiratory medicine. London: BMJ Books, 2005. pp 91-105.

5. Greaves CJ, Hyland ME, Halpin DMG, Blake S, Seamark D. Patterns of corticosteroid medication use: non-adherence can be effective in milder asthma. Prim Care Respir J 2005;14:99-105. http://dx.doi.org/10.1016//.pcri.2004.09.005

6. Hyland ME. The origins of health and disease. Cambridge: Cambridge University
Press, 2011. http://dx.doi.org/10.1017/СBO9780511976216

7. Juarrero A. Dynamics in action: intentional behavior as a complex system. Cambridge, MA: MIT Press, 1999.

8. Hyland ME. The intelligent body and its discontents. J Health Psychol 2002; 7:21-32. http://dx.doi.org/10.1177/1359105302007001649

9. Hyland ME. A two-phase network theory of asthma causation: a possible solution to the impact of genes, hygiene and air quality. Clin Exp Allergy 2001;31:1485-92. http://dx.doi.org/10.1046/j.1365-2222.2001.01234.x

10. StataCorp. Stata Statistical Software: Release 12. College Station, TX: StataCorp LP, 2011.

11. Office for National Statistics. Key Statistics. East Devon 002 (Middle Layer Super Output Area). 2001. http://www.neighbourhood.statistics.gov.uk/dissemination/ LeadKeyFigures. $d o ? a=7 \& b=281304 \& c=E X 14+2 D D \& d=140 \& e=15 \& g=435909 \& i=1$ 001 $\times 1003 \times 1004 \& \mathrm{~m}=0 \& \mathrm{r}=0 \& \mathrm{~s}=1335960720198 \& e n c=1$ (accessed 2 May 2012).

12. Vuong QH. Likelihood ratio tests for model selection and non-nested hypotheses. Econometrica 1989;57:307-33. http://dx.doi.org/10.2307/1912557

13. Papi A, Canonica GW, Maestrelli $P$, et al. Regular use of beclomethasone and albuterol in a single inhaler for mild asthma. N Engl J Med 2007;356:2040-52. http://dx.doi.org/10.1056/NEJMoa063861

14. Boushey HA, Sorkness CA, King TS, et al. Daily versus as needed corticosteroids for mild persistent asthma. N Engl J Med 2005;352:1519-28. http://dx.doi.org/10.1056/NEJMoa042552

15. Martinez FD, Chinhilli VM, Morgan WJ, et al. Use of beclomethasone dipropionate as rescue treatment for children with mild persistent asthma (TREXA): a randomised, double-blind, placebo-controlled trial. Lancet 2011;377:650-7. http://dx.doi.org/10.1016/S0140-6736(10)62145-9

16. Hyland ME, Blake $S$, Greaves $C J$, et al. Guidelines versus practice: UK asthma nurses often recommend intermittent, symptom driven use of inhaled corticosteroids. Prim Care Respir J 2009;18:114-17.

17. Segerstrom SC, Miller GE. Psychological stress and the human immune system: a meta-analytic study of 30 years of inquiry. Psychol Bull 2004;130:601-30. http://dx.doi.org/10.1037/0033-2909.130.4.601

18. Irwin RR. Human psychoneuroimmunology: 20 years of discovery. Brain Behav Immun 2008;22:129-39. http://dx.doi.org/10.1016/j.bbi.2007.07.013

19. Kiecolt-Glaser JK, McGuire L, Robles TF, Glaser R. Psychoneuroimmunology: psychological influences on immune function and health. J Consult Clin Psychol 2002;70:537-47. http://dx.doi.org/10.1037/0022-006X.70.3.537

20. Kemeny ME, Schedlowski M. Understanding the interaction between psychological stress and immune-related diseases: a stepwise progression. Brain Behav Immun 2007;21:1009-18. http://dx.doi.org/10.1016/j.bbi.2007.07.010

21. Whalley $B$, Jacobs $P$, Hyland ME. Correlation of psychological and physical symptoms with chronically elevated cytokine levels associated with a common immune dysregulation. Ann Allergy Asthma Immunol 2007;99:348-51. http://dx.doi.org/10.1016/\$1081-1206(10)60551-0

22. Joachim RA, Noga $O$, Sagach $V$, et al. Correlation between immune and neuronal parameters and stress perception in allergic asthmatics. Clin Exp Allergy 2007;38:283-90. http://dx.doi.org/10.1111/j.1365-2222.2007.02899.x

23. ten Brinke A, Sterk PJ, Masclee AAM, et al. Risk factors of frequent exacerbations in difficult asthma. Eur Respir J 2005;26:812-18. http://dx.doi.org/10.1183/09031936.05.00037905

24. Mancuso CA, Wenderoth S, Westermann H, Choi TN, Briggs W, Charlson ME. Patient-reported and physician reported depressive conditions in relation to asthma severity and control. Chest 2008;133:1142-8.

http://dx.doi.org/10.1378/chest.07-2243

\section{Available online at http://www.thepcrj.org}


STROBE Statement_checklist of items that should be included in reports of observational studies

\begin{tabular}{|c|c|c|}
\hline & $\begin{array}{c}\text { Item } \\
\text { No } \\
\end{array}$ & Recommendation and Response \\
\hline \multirow[t]{2}{*}{ Title and abstract } & 1 & $\begin{array}{l}\text { (a) Indicate the study's design with a commonly used term in the title or the abstract } \\
\text { The title specifies that it is an observational study }\end{array}$ \\
\hline & & $\begin{array}{l}\text { (b) Provide in the abstract an informative and balanced summary of what was done } \\
\text { and what was found } \\
\text { The structured abstract provides this detail }\end{array}$ \\
\hline \multicolumn{3}{|l|}{ Introduction } \\
\hline Background/rationale & 2 & $\begin{array}{l}\text { Explain the scientific background and rationale for the investigation being reported } \\
\text { The study is based on a theoretically derived prediction about dysregulated people. } \\
\text { This is specified }\end{array}$ \\
\hline Objectives & 3 & $\begin{array}{l}\text { State specific objectives, including any prespecified hypotheses } \\
\text { This is done }\end{array}$ \\
\hline \multicolumn{3}{|l|}{ Methods } \\
\hline Study design & 4 & $\begin{array}{l}\text { Present key elements of study design early in the paper } \\
\text { This is done }\end{array}$ \\
\hline Setting & 5 & $\begin{array}{l}\text { Describe the setting, locations, and relevant dates, including periods of recruitment, } \\
\text { exposure, follow-up, and data collection } \\
\text { We give the dates of all points of data collection }\end{array}$ \\
\hline \multirow[t]{2}{*}{ Participants } & 6 & $\begin{array}{l}\text { (a) Cohort study - Give the eligibility criteria, and the sources and methods of } \\
\text { selection of participants. Describe methods of follow-up } \\
\text { We describe the follow up over } 5 \text { years using manual search of patient notes } \\
\text { Case-control study - Give the eligibility criteria, and the sources and methods of } \\
\text { case ascertainment and control selection. Give the rationale for the choice of cases } \\
\text { and controls } \\
\text { Cross-sectional study - Give the eligibility criteria, and the sources and methods of } \\
\text { selection of participants } \\
\text { We provide details of the inclusion - all patients who were prescribed ICS }\end{array}$ \\
\hline & & $\begin{array}{l}\text { (b) Cohort study-For matched studies, give matching criteria and number of } \\
\text { exposed and unexposed } \\
\text { Case-control study-For matched studies, give matching criteria and the number of } \\
\text { controls per case }\end{array}$ \\
\hline Variables & 7 & $\begin{array}{l}\text { Clearly define all outcomes, exposures, predictors, potential confounders, and effect } \\
\text { modifiers. Give diagnostic criteria, if applicable } \\
\text { We define the outcome variable - unscheduled asthma contact with a doctor. }\end{array}$ \\
\hline $\begin{array}{l}\text { Data sources/ } \\
\text { measurement }\end{array}$ & $8^{*}$ & $\begin{array}{l}\text { For each variable of interest, give sources of data and details of methods of } \\
\text { assessment (measurement). Describe comparability of assessment methods if there } \\
\text { is more than one group } \\
\text { We provide the method of developing our scoring procedure }\end{array}$ \\
\hline Bias & 9 & $\begin{array}{l}\text { Describe any efforts to address potential sources of bias } \\
\text { We refer to two methods of assessing adherence - and refer to the bias associated } \\
\text { with each }\end{array}$ \\
\hline Study size & 10 & $\begin{array}{l}\text { Explain how the study size was arrived at } \\
\text { The sample size was determined by the practice. }\end{array}$ \\
\hline Quantitative variables & 11 & Explain how quantitative variables were handled in the analyses. If applicable, \\
\hline
\end{tabular}




\section{Appendix 1}

describe which groupings were chosen and why

$N / A$

Statistical methods

12 (a) Describe all statistical methods, including those used to control for confounding This is done

(b) Describe any methods used to examine subgroups and interactions This done

(c) Explain how missing data were addressed

The only missing data is if patient records are unavailable for the full five years, and we explain how we handle this

(d) Cohort study - If applicable, explain how loss to follow-up was addressed Case-control study-If applicable, explain how matching of cases and controls was addressed

Cross-sectional study - If applicable, describe analytical methods taking account of sampling strategy

(e) Describe any sensitivity analyses

We describe this

Continued on next page 


\section{Appendix 1}

\section{Results}

\begin{tabular}{|c|c|c|}
\hline \multirow[t]{3}{*}{ Participants } & $13 *$ & $\begin{array}{l}\text { (a) Report numbers of individuals at each stage of study—eg numbers potentially eligible, } \\
\text { examined for eligibility, confirmed eligible, included in the study, completing follow-up, and } \\
\text { analysed } \\
\text { This is done }\end{array}$ \\
\hline & & (b) Give reasons for non-participation at each stage \\
\hline & & (c) Consider use of a flow diagram \\
\hline \multirow[t]{3}{*}{$\begin{array}{l}\text { Descriptive } \\
\text { data }\end{array}$} & $14 *$ & $\begin{array}{l}\text { (a) Give characteristics of study participants (eg demographic, clinical, social) and information } \\
\text { on exposures and potential confounders }\end{array}$ \\
\hline & & (b) Indicate number of participants with missing data for each variable of interest \\
\hline & & $\begin{array}{l}\text { (c) Cohort study-Summarise follow-up time (eg, average and total amount) } \\
\text { We provide details of the number of patients for whom we had the full five years of data, and } \\
\text { those we did not. }\end{array}$ \\
\hline \multirow[t]{3}{*}{ Outcome data } & $15^{*}$ & $\begin{array}{l}\text { Cohort study-Report numbers of outcome events or summary measures over time } \\
\text { All provided }\end{array}$ \\
\hline & & $\begin{array}{l}\text { Case-control study-Report numbers in each exposure category, or summary measures of } \\
\text { exposure }\end{array}$ \\
\hline & & $\begin{array}{l}\text { Cross-sectional study - Report numbers of outcome events or summary measures } \\
\text { All provided }\end{array}$ \\
\hline \multirow[t]{3}{*}{ Main results } & 16 & $\begin{array}{l}\text { (a) Give unadjusted estimates and, if applicable, confounder-adjusted estimates and their } \\
\text { precision (eg, } 95 \% \text { confidence interval). Make clear which confounders were adjusted for and } \\
\text { why they were included } \\
\text { All provided }\end{array}$ \\
\hline & & $\begin{array}{l}\text { (b) Report category boundaries when continuous variables were categorized } \\
\text { We explain why we place boundaries where we do }\end{array}$ \\
\hline & & $\begin{array}{l}\text { (c) If relevant, consider translating estimates of relative risk into absolute risk for a meaningful } \\
\text { time period }\end{array}$ \\
\hline Other analyses & 17 & $\begin{array}{l}\text { Report other analyses done-eg analyses of subgroups and interactions, and sensitivity } \\
\text { analyses }\end{array}$ \\
\hline \multicolumn{3}{|l|}{ Discussion } \\
\hline Key results & 18 & $\begin{array}{l}\text { Summarise key results with reference to study objectives } \\
\text { Done }\end{array}$ \\
\hline Limitations & 19 & $\begin{array}{l}\text { Discuss limitations of the study, taking into account sources of potential bias or imprecision. } \\
\text { Discuss both direction and magnitude of any potential bias }\end{array}$ \\
\hline Interpretation & 20 & $\begin{array}{l}\text { Give a cautious overall interpretation of results considering objectives, limitations, multiplicity } \\
\text { of analyses, results from similar studies, and other relevant evidence }\end{array}$ \\
\hline Generalisability & 21 & Discuss the generalisability (external validity) of the study results \\
\hline \multicolumn{3}{|c|}{ Other information } \\
\hline Funding & 22 & $\begin{array}{l}\text { Give the source of funding and the role of the funders for the present study and, if applicable, } \\
\text { for the original study on which the present article is based } \\
\text { Done }\end{array}$ \\
\hline
\end{tabular}

* Give information separately for cases and controls in case-control studies and, if applicable, for exposed and unexposed groups in cohort and cross-sectional studies 
Appendix 1

Note: An Explanation and Elaboration article discusses each checklist item and gives methodological background and published examples of transparent reporting. The STROBE checklist is best used in conjunction with this article (freely available on the Web sites of PLoS Medicine at http://www.plosmedicine.org/, Annals of Internal Medicine at http://www. annals.org/, and Epidemiology at http://www.epidem.com/). Information on the STROBE Initiative is available at www.strobe-statement.org 


\section{Appendix 2}

Supplementary data: Pen portraits of exacerbating patients

As a supplementary data analysis we examined the notes of the 15 patients with the highest number of exacerbations. For ethical reasons we present these data in aggregated form.

1. Five patients had between 20 and 9 exacerbations over the five years. Of these patients:

a. 5 were female

b. 3 had depression and one anxiety, 3 prescribed SSRIs.

c. Excluding asthma and with psychological problems counted as once only: 4 had two and 1 had three or more health problems. Somatic health problems included hypertension, diabetes, palpitations, hypothyroid, hearing loss, migraines

d. 2 were smokers, 3 smokers

e. All were married

2. Five patients had either 6 or 5 exacerbations over the five years. Of these patients.

a. 5 were female

b. 3 had depression, of whom 2 also had anxiety and 1 also had pyschosis. 3 were prescribed SSRIs. A further 1 was autistic with substantial community support.

c. Excluding asthma and with psychological problems counted as once only: 3 had one health problem, 1 had two, and 1 had three or more health problems. Health problems included Type 2 diabetes, chronic back pain, chronic fatigue syndrome

d. 5 were non-smokers

e. 4 were married, 1 divorced

f. 1 patient was obese, and 1 patient a parasuicide

3. Five patients had either 4 or 3 exacerbations over the five years, of whom 4 had 4 exacerbations and 1 had 3 exacerbations. Of these patients

a. 5 were female 


\section{Appendix 2}

b. 3 had depression of whom 1 also had anxiety. 3 were prescribed SSRIs.

c. Excluding asthma and with psychological problems counted as once only: 2 had no problems 2 had two and 1 three or more health problems. Health problems included epilepsy, eczema, arthritis, hypothyroid

d. 3 were ex-smokers and 2 non-smokers.

e. 2 were married, 1 divorced, 1 single and 1 bereaved.

f. 1 patient was obese and 1 a parasuicide 